\title{
Perception of Academics Regarding the Credibility of Online Resources: Open Access versus Subscribed Journals with Special Reference to Eastern University, Sri Lanka
}

\author{
M. Norman Ravikumar ${ }^{1}$ \\ T. Ramanan ${ }^{2}$
}

\begin{abstract}
Electronic information resources can be either credible or unreliable. Vast majority of information on the Internet is neither authenticated nor having any mechanism to validate its credibility. Thus, it has been a great challenge for any researcher who uses them for their problem-solving. Education and research institutions use and contribute to the development of academic journals that broadly fall under two categories, namely subscribed and open access. In this regard, this paper discusses about the views of academics of Eastern University, Sri Lanka depending on these resources for using and publishing their research work. Particularly, this study investigates about the perception of academics over subscription journals and open access resources in regard to their accessibility, visibility and credibility. Summary of results show that researchers hold high value for online subscribed journals in terms of their credibility, meanwhile accessibility to the same is quite a challenge. On the other hand, open access journals give rise to visibility and affordability. Therefore, authors shed light on the need of making open access resources more credible.
\end{abstract}

Keywords: Credibility, Anti-plagiarism, Online Subscribed journals, Open Access Resources

\section{Introduction}

Online information resources are highly important for academics who are involved in teaching, research and publication. With increased technological advancement and the Internet facilities, the degree of using and surfing online resources for obtaining information is steadily increased. However, not all the accessible online resources are accurate and true. This will lead to huge impacts on society especially in the academic user community.

It is needless to say that the Internet has become an inseparable tool to access the information in everyday life at office and home. This has been intensified in the

\footnotetext{
${ }^{1}$ Senior Assistant Librarian, Eastern University, Sri Lanka, E-mail: ravimnr@mail.com, (D) https://orcid.org/0000-0002-2243-880X

${ }^{2}$ McMaster University, One James North Street, Hamilton, Ontario, Canada, E-mail: thankavr@mcmaster.ca
} 
recent decade as the access to information is perceived vital (Metzger, 2007). On the other hand, the quality and credibility of the information on the web resources are also of great concern for online users. Emergence of journals and databases at exponential growth has blurred the credibility line. Mashroofa (2015) stated that compared with other countries utilization of open access data by the Sri Lankan scholars is low in volume. Further, it is emphasized on proper awareness programme that need to be conducted for research scholars by learning the perception of academics, researchers, librarians and policy makers towards open access resources.

Therefore, it is essential to make the users aware of the difference between authenticated and dubious online resources. Besides, promotion schemes and procedures compel the academics to possess merits in research and publication. This often leads to hasty decisions to use and publish in unauthenticated journals.

Therefore, measuring the level of awareness and perception of users in relation to the Internet resources is the first step to plan the training programme and workshop modules by the library professionals in Sri Lanka. These training sessions will increase the accumulation of credible online resources by means of creating, developing and promoting authenticated research publications.

\section{Literature Review}

\section{Use of the Internet}

Based on the International Telecommunication Union (ITU) statistical report Sri Lanka has 6,710,160 internet users as of December, 2018 which is $31.9 \%$ of the total population (www.internetworldstats.com/asia.htm\#lk). This figure is assumed to increase further by subsequent years provided almost all the age groups in the country are in possession of smart phones.

Moreover, the statistics released by Telecommunication Regulatory Commission of Sri Lanka (TRC) says that the number of mobile broadband connections doubled every year. It has an average growth of nearly $96.5 \%$ in the past six years. Fixed internet connections also showed a growth of 68\% (http://trc.gov.lk/2014-05-13-0356-46/statistics.html). 


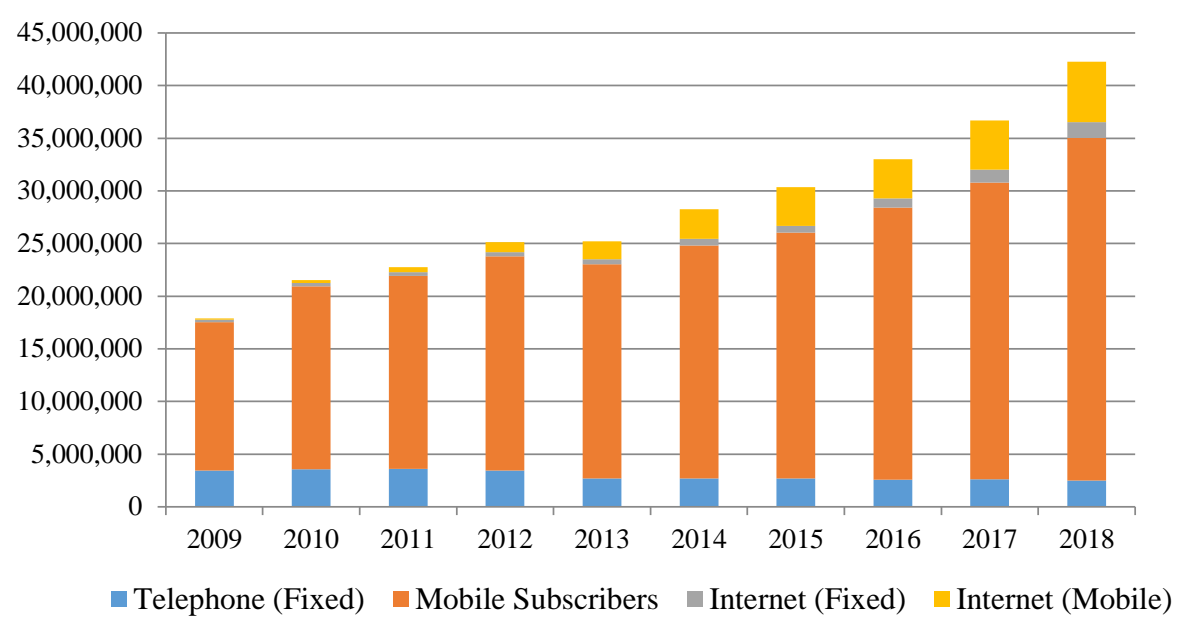

Figure 1. Internet usage statistics in Sri Lanka

(Source: http://www.trc.gov.lk/2014-05-13-03-56-46/statistics.html)

Provided the Internet use has increased in width and depth in Sri Lanka (as shown in the above figure), the likelihood of increased use of online information is highly evinced among its citizens, especially the students of different levels of education. While having its advantages, the Internet poses severe demerits in terms of toxic and unreliable information.

According to Conners (2019), as of 2018, over 1.8 billion websites in the world are protected by free speech and anti-censorship laws. That connotes the owners (of electronic resources) can publish anything, whether they are true or fake, with no concern about the consequences. This also holds true in research and educational realms.

And, access to information made available by the Internet facility has the possibilities to alter the way young generations perceive their surrounding (Shahibi \& Mazlan, 2003). This is woven with intentional or unintentional dissemination of false knowledge and uncertain information.

\section{Credibility of Online Information}

Credibility is one of the criteria used to measure the authenticity of information (Wathen \& Burkell, 2002). This has become more serious as the information on the Internet is spread easily without being evaluated or monitored by any authorities on its credibility. Researchers are investigating the difference between old mass media and modern tools of information access.

Credibility was earlier defined as the reliability of sources that was conceptualized around the believability of authors and publishers (Metzger \& Flanagin, 2013). Source of information has a degree of trustworthiness by the audience, where higher source prestige is closely related to the likelihood that people will agree with contents 
(Hovland \& Weiss, 1951). Later, credibility of information became the prime concern due to research in information sciences (Metzger \& Flanagin, 2013). In this regard, it is important for researchers to consider the credibility of source and communicator when it comes to using and publishing the information.

According to the research done by Kousha and Thelwall (2017) that information and citation of Wikipedia resources are useful new source of evidence in terms of general knowledge with non-scholarly impacts. Mostly, their use is prominent in the arts and humanities due to its advantage of open access where anyone with internet access can edit them.

Hence, information sources that are conferred on by university students and academics need to be evaluated for their credibility so that the access and dissemination of knowledge will be genuine. Online subscribed journals and databases have already established their source-reputation among academics; however open access movement struggles to earn the trust and credibility for its journals.

\section{Subscribed Versus Open Access}

Disputes against open access publishing are concentrating at their quality of peerreviewing systems. Since subscribed journals charge article processing fees (APC) from authors it is believed the renowned reviewers are cherry-picked by the popular publishers, whereas open access journals charge less or no APC thus the quality of peer review is debated by scholars. However, it was found that open access journals indexed in Web of Science and Scopus have same impact and quality as the subscribed journals (Björk \& Solomon, 2012).

Björk and Solomon (2012) record that BioMedCentral and Public Library of Science (PLoS) was the first Open Access (OA) publishers to manage their operation by charging article processing charges from authors. Meanwhile, this business model of publishers impedes authors from submitting their articles in OA journals.

It is common grounds that libraries and researchers cannot afford to subscribe to commercial journals (Ghane \& Niazmand, 2016). How do libraries then assure that credible research information is being effectively circulated amongst its users?

\section{Peer Review Quality and Sustainability}

In the latter half of the 1990s when journals created by individual scientists were dominating OA publishing, these journals were not considered by most academics a serious alternative to subscription publishing. There were doubts about both the sustainability of the journals and the quality of the peer review. These journals were usually not indexed in the Web of Science, and initially they lacked the prestige that academics need from publishing (Björk \& Solomon, 2012). 


\section{Objectives}

To explore about the perception of academics in Eastern University, Sri Lanka who use and publish in both open access and online subscribed journals with following specific objectives.

- To learn as to what type of online resources the academic prefer;

- To investigate the perception of credibility of both subscribed and open access journals; and

- To find out the relationship between staff position and their preference of journal types.

\section{Methodology}

Survey method administering structured-questionnaire was used in this study. As the total population is 196, no sampling technique was adopted, thus all academic staff of Eastern University, Sri Lanka (EUSL) were approached with an online questionnaire. $85.20 \%$ of the respondents had answered. Responses were obtained from Research Support Service (RSS) workshops and training sessions conducted by Senior Assistant Librarians for different faculty members. The authors extracted the threads from feedback and Q\&A sessions of participants at workshops conducted at Eastern University, Sri Lanka. Mean values in descriptive statistics were used to infer on the responses. Likert scale was used to draw the analysis of statements of the subjects. Correlation between variables was run using Cramer's V. Qualitative analysis of opinion survey (carried out through telephone with key-persons) has enumerated the various views of academics on challenges in accessing to and publishing in electronic journals.

Response Rate

Faculty-wise Responses

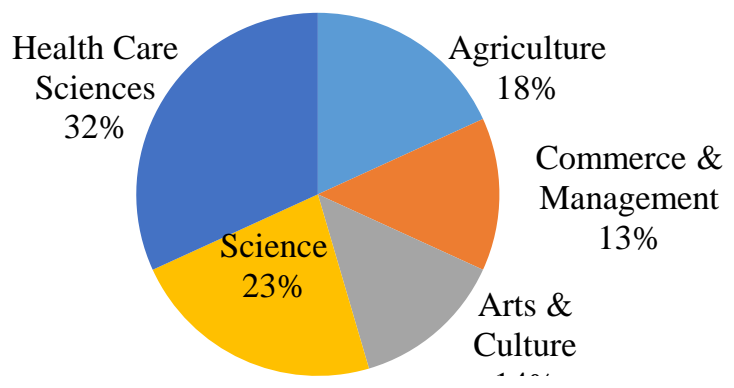

Figure 2. Faculty-wise Responses

Figure 2 depicts that higher number of academics from Faculty of Health Care Sciences had responded to the questionnaire, followed by Faculty of Science and Faculty of Agriculture, respectively. Response rate was relatively low for Faculty of Arts and Culture, and Faculty of Commerce and Management although the staff 
number is high in those entities. This depicts STEM faculties are more active on electronic media than faculties of humanities. Respondents stated that there is very narrow presence of authenticated literature in Tamil on the Internet.

\section{Education Level of Respondents}

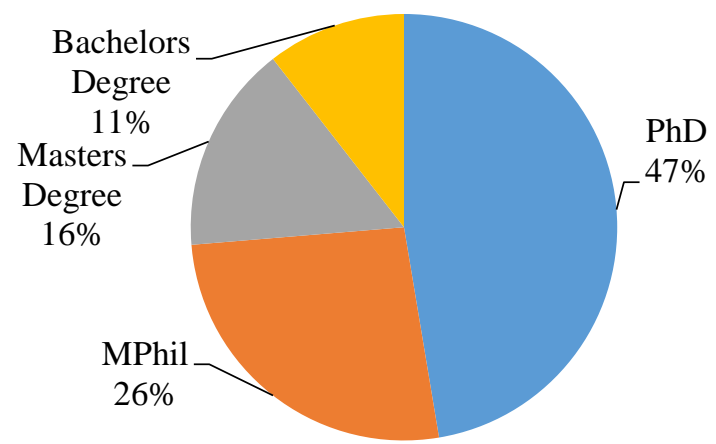

Figure 3. Education Level of Respondents

According to Figure 3, majority of the respondents (47\%) were $\mathrm{PhD}$ holders followed by MPhil (26\%) holders. This evinces more PhD holders followed by MPhil respondents have expressed their concerns over the objectives of this study.

Position of Respondents in the University

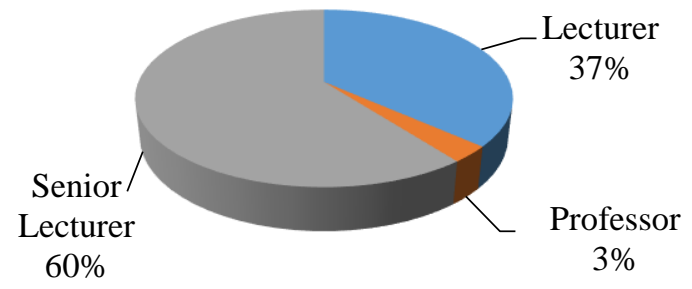

Figure 4. Position of respondents

Figure 4 reveals that majority of the respondents $(60 \%)$ were Senior Lectures followed by Lecturers (37\%) in the University.

Preferred form of Journal of the Academics

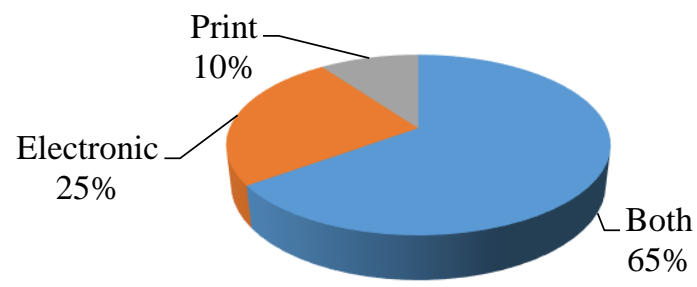

Figure 5. Preferred form of Journal 
It was intended to know about the preferred form of journals used by the academics for their preference. Figure 5 shows that majority (65\%) of the academics prefer both print and electronic journals for their information needs. Obstacles to accessing reputed online subscribed journals compel the academic to use available print resources.

\section{Electronic Information Resources Used for Research by EUSL Academics}

\section{E-journals}

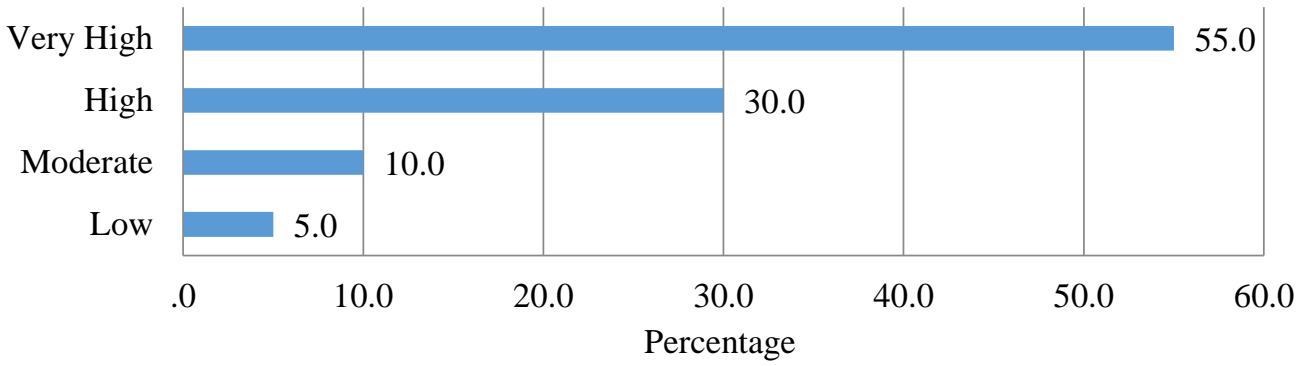

Figure 6. E- Journal Usage

Despite the fact that there are only a few subscribed journals (both online and in print) available to the academics of Eastern University, Sri Lanka they are preferably using electronic journals. Figure 6 shows that the majority of academics have inclined to using electronic journals. Reputation and visibility of those e-journals facilitate this trend.

\section{Electronic Repositories}

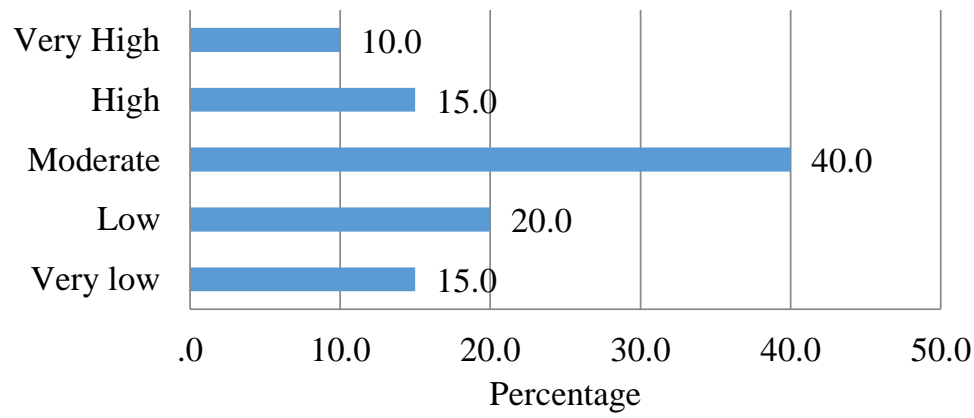

Figure 7. E- Repository Usage

It is observed that majority of respondents (40\%) have moderately used electronic repositories for their information needs. This reveals that more awareness is needed to promote the use of electronic repositories in research and publication. 
Wikipedia

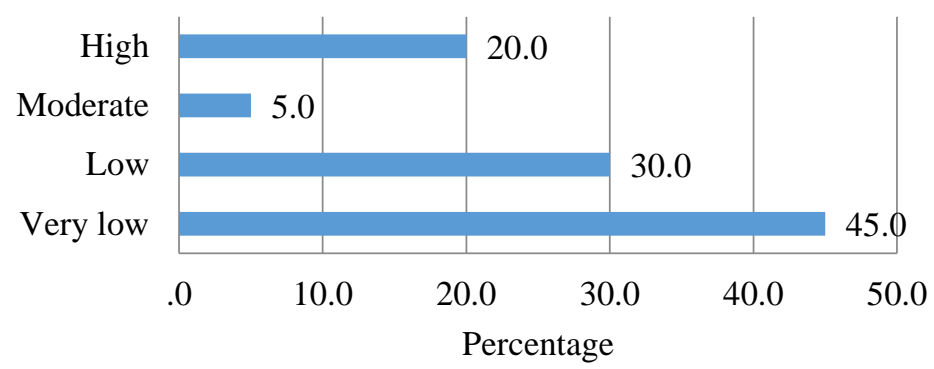

Figure 8. Wikipedia Usage

The above figure clearly shows that majority of the academics (45\%) were not interested in using the information obtained from Wikipedia for their research work. The main purpose of using Wikipedia is to grasp an idea of the topic concerned. This is an assurance in terms of credibility of information usage as Wikipedia is not perceived as an academically authenticated source based on the results (Kousha \& Thelwall, 2017).

\section{Online Statistics}

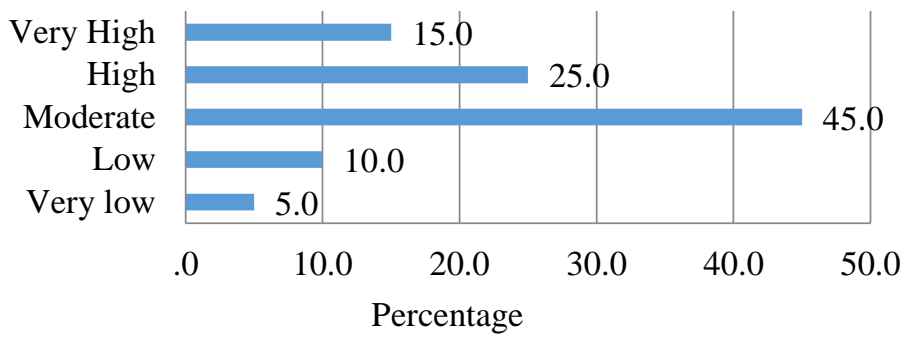

Figure 9. Online Statistics Usage

It was identified that most of the academics are using statistics obtained from the internet moderately in their research publications. However, it is obvious statistical data from unverified sources are numerous on the Internet.

Websites

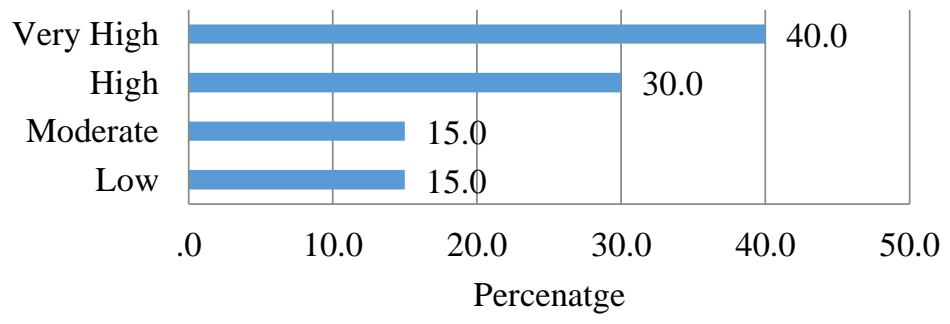

Figure 10. Website Usage 
The above figure 10 shows that information obtained from websites were highly used by the academics while publishing their research. Key-person interviews show that respondents are not much aware of the authentication of those resources. This emphasizes on more training needed to increase the use of credible information resources.

Usage of Subscribed Online Databases/Journals

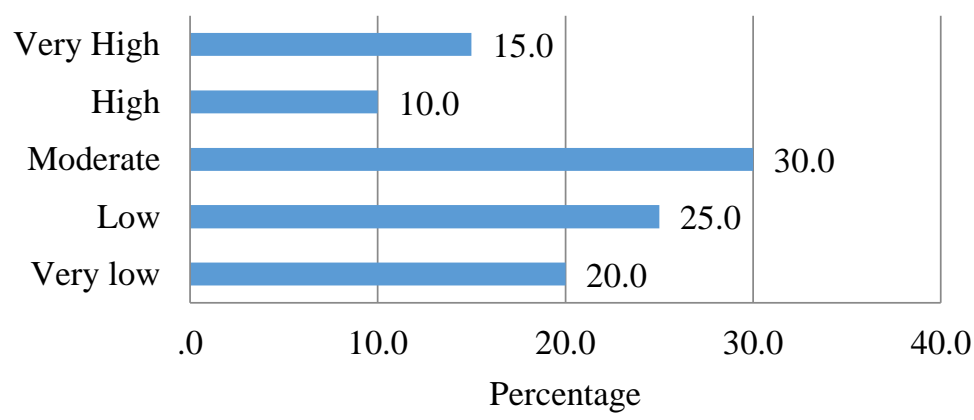

Figure 11. Online Databases Usage

Eastern University has access to four databases offered by the UGC. In-addition, EUSL has subscribed to Researh4Life databases for the use of academics and students. Figure 11 reveals that online databases are considerably highly used by the academics of EUSL. Therefore, if provided with more resources, the researchers are willing to use credible resources.

Usage of Open Access Databases/Journals by EUSL Academics

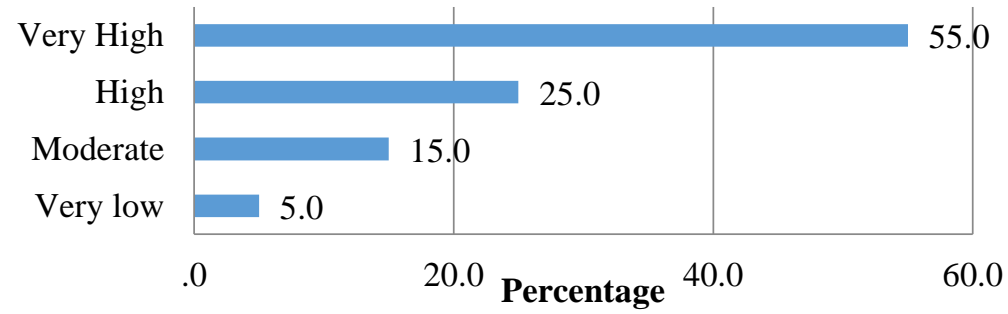

Figure 12. Open Access Databases Usage

It was intend to identify the usage of freely available open access journals / database by the EUSL academics and it was identified that majority (80\%) of the academics were used open access journals/database for their research.

Perception on Credibility of Online Information by the academics of EUSL

Results of a telephone interview with key participants of the study show that academics are convenient of and preferring to use electronic journals and online 
information resources for their research. However, they have expressed their concerns over dubious sources of research information.

Preferred form of Journal for Publishing Research Articles

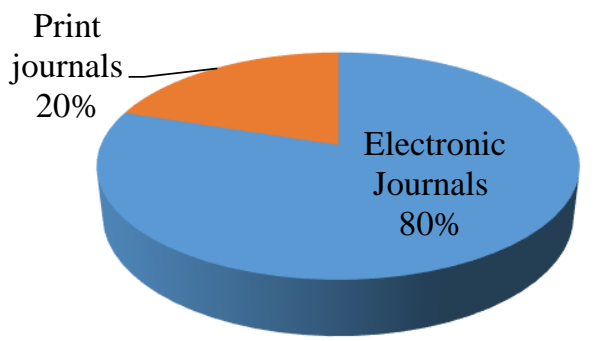

\section{Figure 13. Preferred form of Journal for Publishing}

Figure 13 clearly shows that majority (80\%) of the academics preferred to publish their research in electronic journals than print journals. They feel that electronic journals are more visible to readers than print versions. Visibility also contributes to citation, h-index and journal impact factors.

Most Preferable Type of Electronic Journal to Publish Research Articles

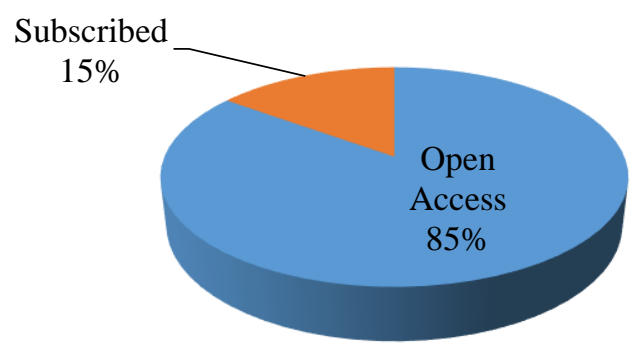

Figure 14. Preferred form of Journal for Publishing

The above figure indicates that $85 \%$ of the academics preferred to publish their research articles in Open Access journals than closed accessed. This has been due to higher rates of article processing charge of reputed journals with high impact factors.

When Cramer's correlation analysis was run to assess the relationship between academic position of respondents and the types of journals they like to publish their research (online subscribed and OA journals) the results as shown in Table 1(a) and 1(b) below. 
Table 1(a): Cross tabulation between academic position and most preferable type of journal for their publication

\begin{tabular}{|c|c|c|c|c|c|}
\hline & \multicolumn{2}{|c|}{$\begin{array}{l}\text { Most preferable type of } \\
\text { journal }\end{array}$} & \multirow{2}{*}{ Total } \\
\hline & & & $\begin{array}{l}\text { Open Access } \\
\text { Journals }\end{array}$ & $\begin{array}{c}\text { Subscribed } \\
\text { Journals }\end{array}$ & \\
\hline \multirow[t]{6}{*}{ Position } & \multirow[t]{2}{*}{ Lecturer } & Count & 46 & 15 & 61 \\
\hline & & $\%$ within Position & $75.4 \%$ & $24.6 \%$ & $100.0 \%$ \\
\hline & \multirow[t]{2}{*}{ Professor } & Count & 1 & 4 & 5 \\
\hline & & $\%$ within Position & $20.0 \%$ & $80.0 \%$ & $100.0 \%$ \\
\hline & \multirow{2}{*}{$\begin{array}{l}\text { Senior } \\
\text { Lecturer }\end{array}$} & Count & 84 & 17 & 101 \\
\hline & & $\%$ within Position & $83.2 \%$ & $16.8 \%$ & $100.0 \%$ \\
\hline \multirow[t]{2}{*}{ Total } & & Count & 131 & 36 & 167 \\
\hline & & $\%$ with & $78.4 \%$ & $21.6 \%$ & $100.0 \%$ \\
\hline
\end{tabular}

Table 1(b): Symmetric Measures

\begin{tabular}{|c|r|r|}
\hline & \multicolumn{1}{|c|}{ Value } & Approx. Sig. \\
\hline Phi & .265 & .000 \\
Cramer's V & .265 & .000 \\
N of Valid Cases & 167 & \\
\hline
\end{tabular}

This strongly evinces that there is a reasonably strong relationship between academic position and their most preferable type of journal for the publication (Cramer's $\mathrm{V}=0.265)$. Therefore, it is inferred that the professor grade academics prefer subscribed journals to publish their work whereas lecturers and senior lecturers are more inclined to open access journals. On one hand, professors select online subscribed journals to maintain their reputation in the field. On the other, senior lecturers and lecturers are on the run to increase the visibility of their publications so they prefer OA journals.

\section{Satisfaction with Available e-Journal Databases}

All universities in Sri Lanka gain access to online database which are offered by the University Grant Commission under the Consortium for Academic Libraries (CONSAL). Eastern University also has access to four databases namely Emerald, Oxford University Press, Wiley Online Journals and Sage Research Methods offered through CONSAL. In-addition, EUSL has subscribed to Researh4Life database which offers mainly two databases namely HINARI and AGORA for the use of academics and students. Therefore, it was indented to identify the satisfaction of academics on these available subscribed databases. 


\section{Table 2. Mean value of Satisfaction about available databases}

\begin{tabular}{|l|c|}
\hline Database & Mean \\
\hline Emerald & 3.75 \\
\hline Wiley Online & 3.70 \\
\hline HINARI & 3.70 \\
\hline Sage Research Methods & 3.65 \\
\hline Oxford University Press & 3.55 \\
\hline AGORA & 3.50 \\
\hline
\end{tabular}

Likert five point scale starting from 1 - very dissatisfied to 5- very satisfied was used to get the response of academics and Table 2 reveals the mean values obtained for the responses. According to that it was found that academics were highly satisfied with Emerald database followed by Wiley Online and HINARI.

\section{Research Sharing}

It was decided to identify whether the academics are interested in sharing their research and results with other academics and researchers. To identify that following variables were identified and the results were analyzed.

\section{Usage of Cloud Storage Facilities}

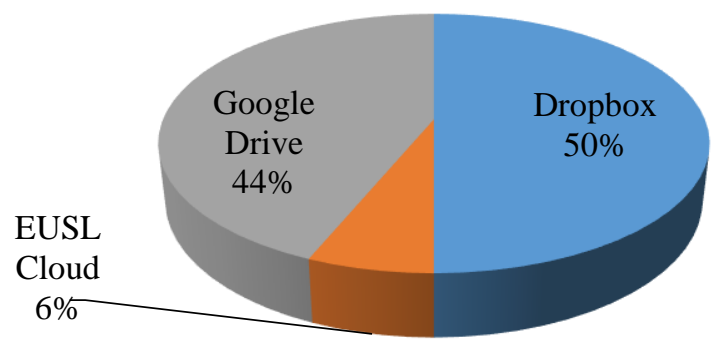

\section{Figure 15. Different type of cloud storage facilities used by academics}

Figure 15 clearly shows that Dropbox and Google drive were used by majority of academics for sharing purposes. And, only few academics used EUSL Cloud service for sharing research. Virtual storage spaces are very helpful to researchers to expand the time invested on research and publication. Moreover, tools like Google Drive facilitate inter-university and interdisciplinary research initiatives (Liu \& Dong, 2012). 
Sharing Research Papers in Social Networks

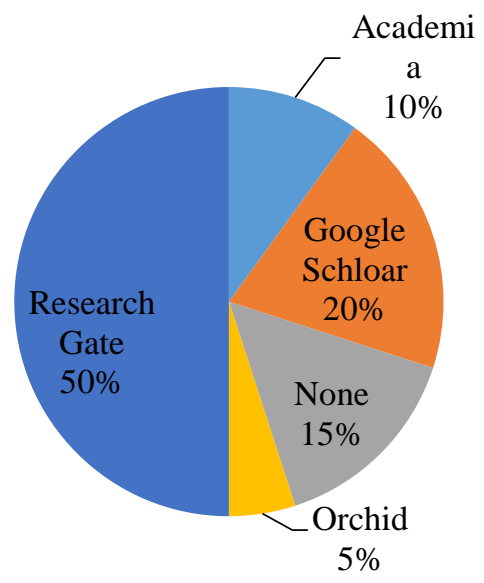

Figure 16. Research papers shared in social networks

As alternative to sharing research work on subscribed research platforms, researchers and academics are using scholarly social networks to increase the visibility. Figure 16 shows majority of the academics shared their research papers in Research Gate (50\%) followed by Google Scholar (20\%). At the same time 15\% of the academics were not sharing their research in any of these social networks. It is identified more awareness is needed to promote this type sharing.

\section{Opinion of Academics Regarding Open Access Publishing}

Likert five point scales starting from 1 highly disagree to 5- highly agree was used to get the opinion of academics on the statements given regarding open access and Table 3 reveals the mean values obtained for the statements.

\section{Table 3. Mean value of statements}

\begin{tabular}{|l|c|}
\hline \multicolumn{1}{|c|}{ Statements } & Mean \\
\hline Open access journals have more visibility for my research & 4.50 \\
\hline Articles in open access journals are authenticated & 4.45 \\
\hline Publishing in open access journals will increase my citation & 4.35 \\
\hline Online subscribed journals are highly reputed than open access journals & 3.85 \\
\hline Publishing in online subscribed journals will increase my citation & 3.75 \\
\hline Plagiarism rate is high in open access journals & 2.85 \\
\hline
\end{tabular}

Table 3 shows most of the academics strongly believe that publishing in open access journals will give more visibility for their research and it will increase their citations. Most of the academics were highly confident about the authentication of open access journals. On contrary, considerable number of respondents believes plagiarism rate is high in open access journals and resources although the subjects say citation rate is 
high in open access journals than in subscribed ones. Also they believe that online subscribed journals are highly reputed than open access.

Funding Sources for Publishing Research

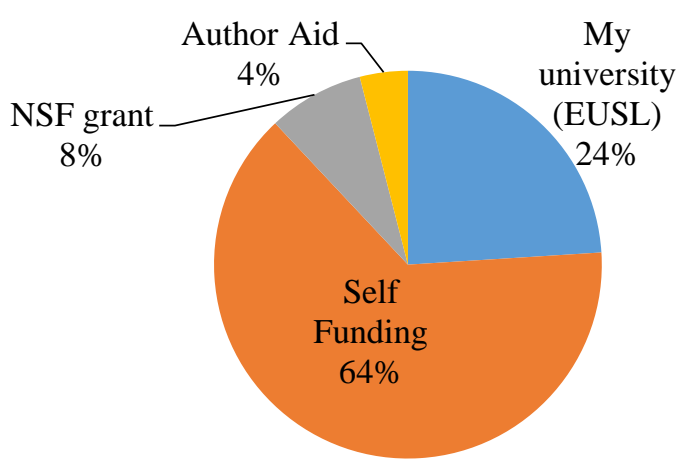

Figure 17. Funding sources

Figure 17 clearly shows that majorities $(64 \%)$ of the academics are using their own funds for publishing their research and $24 \%$ of the academics are using the University funds for publishing their paper. Only a few academics are receiving grants from NSF and Author Aid for publishing.

\section{Conclusions}

Debate on affordability versus visibility draws the deliberate line between subscribed and open access journals. They both serve their objectives, however, it is their credibility and authenticity is the prime concern for any academic institution in Sri Lanka. With the luxuries provided by the Internet it is likely that researchers with limited financial resources tend to believe everything published on the digital platform.

Use of information and integration of information are two different phenomena, where in first case one simply uses the information while in the second occasion only the sensible and authenticated resources will be conferred. In similar vein, information made available online are being either merely used or scrutinized for their credibility.

The study clearly shows that academics of EUSL preferred electronic journals/databases to print materials. Meanwhile, the exploitation of online subscribed journals available at Eastern University, Sri Lanka is comparatively low due to their irrelevant subject coverage. Unawareness of credible journals, lack of search skills, less time spent on research and workload are some of the reasons that hinder the use of electronic journals as the respondents stated during the Research Support sessions conducted by the Senior Assistant Librarians. However, substantial 
number of academics values the electronic journals and OA movement. And, most of the academics are sharing their research in Research gate and Google Scholar.

Only a few academic staff are obtaining research grants for their publications whereas most of others are depending on their own funds. Therefore, increasing awareness on open accesses publication will be beneficial for financially disadvantaged academics. The main challenge here is credibility of information shared on open access resources and social networks. Researchers and librarians need to take great responsibility and proactive initiatives to combat spreading of fake information and dubious journals.

When it comes to credibility online subscribed journals are preferred to open access, whereas visibility factor is stronger on the side of selecting open access journals for publishing. This has been more emphasized by a correlation analysis where professor grade academics state that they incline to online subscribed journals for publishing as their credibility is well established. On the other hand, senior lecturers and lecturers depend on open access journals for publishing their articles, which is attributed to their low or no article processing charges (APC) and visibility. Therefore, further studies and programs should be executed to increase the credibility of open access journals since increasing the visibility of online subscribed journals will always be constrained by their subscription rates.

Finally, implementation of anti-plagiarism software and uncompromising strict review policies on journal publications, continuous evaluation of academic publication by individual institutions and national bodies liaised with the regional and International entities are the measures to curtail unauthenticated information and to promote use of credible research resources.

\section{References}

Björk, B. C., \& Solomon, D. (2012). Open access versus subscription journals: a comparison of scientific impact. BMC Medicine, 10(1), 73. http://doi.org/10.1186/1741-7015-10-73

Conners, Jaramy (2019, May 10). What is a credible source? How to evaluate web resources. $\quad$ Retrieved July 06, 2019 from https://www.whoishostingthis.com/resources/credible-sources/

Ghane, Mohammad Reza \& Niazmand, Mohammad Reza (2016). Current status of open access journals published in D8 countries and registered in the Directory of Open Access Journals (pre-2000 to 2014). The Electronic Library, 34(5), 740756. http://dx.doi.org/10.1108/EL-06-2015-0107

Hovland, C. I. \& Weiss, W. (1951). The Influence of Source Credibility on Communication Effectiveness, Public Opinion Quarterly, 15, 635-650. Retrieved April 18, 2017, from http://faculty.babson.edu/krollag/org_site/soc_psych/hovland_source.html 
Internet World Stats: Usage and Population Statistics (2019, January 20). Retrieved from https://www.internetworldstats.com/asia.htm\#lk

Kousha, K., \& Thelwall, M. (2017). Are wikipedia citations important evidence of the impact of scholarly articles and books? Journal of the Association for Information Science and Technology, 68(3), 762-779. https://doi.org/10.1002/asi.23694

Liu, K., \& Dong, L. (2012). Research on Cloud Data Storage Technology and Its Architecture Implementation. Procedia Engineering, 29, 133-137. https://doi.org/10.1016/j.proeng.2011.12.682

Mashroofa, M. M. (2015). Open Access Revolution: Is it a paradigm shift of scholarly publishing practices? A literature review of global scenario. Journal of the University Librarians Association of Sri Lanka, 19(1), 115-135. http://doi.org/10.4038/jula.v19i1.7878

Metzger, Miriam J. \& Flanagin, Andrew J. (2013). Credibility and trust of information in online environment: the use of cognitive heuristics, Journal of Pragmatics, 59 (2013), 210 - 220, https://doi.org/10.1016/j.pragma.2013.07.012

Metzger, M. J. (2007). Making sense of credibility on the Web: Models for evaluating online information and recommendations for future research. Journal of the American Society for Information Science and Technology, 58(13), 2078-2091. https://doi.org/10.1002/asi.20672

Shahibi, Mohd Sazili \& Mazlan, Mazwani Ayu (2003). Perception towards the credibility of information in Internet among young malay generation, International Journal of Education and Research,1 (7) Retrieved 02 July 2013 from www.ijern.com/journal/July-2013/44.pdf.

Telecommunications Regulatory of Commission of Sri Lanka (2019 January 21). Retrieved from http://trc.gov.lk/2014-05-13-03-56-46/statistics.html

Wathen, C. N., \& Burkell, J. (2002). Believe it or not: Factors influencing credibility on the Web. Journal of the American Society for Information Science and Technology, 53(2), 134-144. https://doi.org/10.1002/asi.10016 